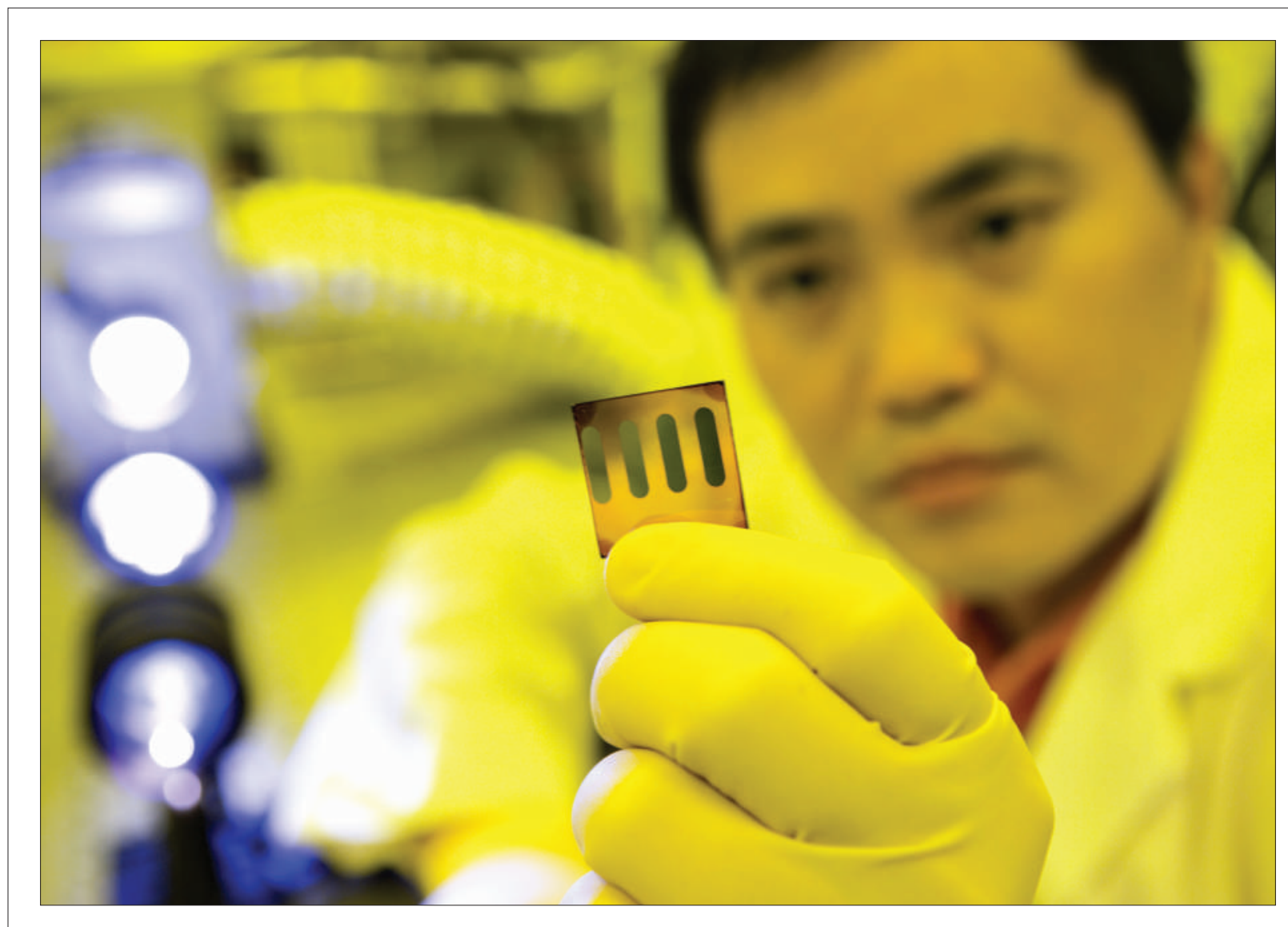

Singapore Journal of

Scientific Research

ISSN: 2010-006x 


\title{
Relation Between Facial and Dental Midlines: An in vivo Study
}

\author{
${ }^{1}$ Veenu Sharma and ${ }^{2}$ Khurshid A. Mattoo \\ ${ }^{1}$ Department of Prosthodontics, Subharti Dental College, SVS University, India \\ ${ }^{2}$ Department of Prosthodontics, College of Dentistry, Jazan University, Saudi Arabia
}

\section{Abstract}

Background and Objective: Facial features are balanced between the right and left side of the face. The facial and dental midline are two most clinically used landmarks to evaluate esthetics in various medical and dental fields. This study evaluated the relation between the two dental midlines and their relation with the facial midline in a particular selected Indo-Aryan ethnic sample. Materials and Methods: About 100 North Indian subjects with an esthetically pleasing face, determined clinically by a five member team of facial esthetics experts were examined for determining the relation between facial and dental midlines using a custom made instrument called facial dental midline relator. Data collected included frequency distribution, mean and standard deviation for all investigated variables. Unpaired test and Karl pearson's correlation coefficient were used to determine statistical significance at a p-value of 0.01 . Results: Maxillary dental midline coincided in $40 \%$ of subjects, while $47 \%$ varied minimally. Dental midlines did not coincide in $60 \%$ of subjects. Mandibular midline showed greater fluctuation with facial midline. The differences between the maxillary dental midline and the facial midline and the mandibular midline with the facial midline showed statistical significance at $p<0.01$. Conclusion: Maxillary dental midline must coincide with facial midline in prosthetic rehabilitation while mandibular midline does not necessarily need to coincide with facial or maxillary dental midline.

Key words: Esthetics, facial symmetry, rhinoplasty, prosthetic dentistry, cosmetic dentistry

Citation: Sharma, V. and K.A. Mattoo, 2020. Relation between facial and dental midlines: An in vivo study. Singapore J. Sci. Res., 10: $363-369$.

Corresponding Author: Khurshid A. Mattoo, Department of Prosthodontics, College of Dentistry, Jazan University, Saudi Arabia Tel: +966595086078

Copyright: ( 2020 Veenu Sharma and Khurshid A. Mattoo. This is an open access article distributed under the terms of the creative commons attribution License, which permits unrestricted use, distribution and reproduction in any medium, provided the original author and source are credited.

Competing Interest: The authors have declared that no competing interest exists.

Data Availability: All relevant data are within the paper and its supporting information files. 


\section{INTRODUCTION}

Human beings have evolved over a period of thousands of years and one of the most distinct evolutionary change that is obvious is that of face. Early skulls presented large cranium in proportion to the face while the size looks more proportional now. Artistic relationships in surface anatomy of human face include an infinite number of line and plane references that can be drawn from one landmark to another'. These relations have widely been used in restoring the natural dentitions be it surgical ${ }^{2}$, restorative ${ }^{3}$, orthodontic ${ }^{4}$, prosthodontic rehabilitations ${ }^{5,6}$ or for forensic studies ${ }^{7,8}$. These relationships are simple, easily remembered and most importantly dynamic in their form. Some of these reference lines and planes are useful for diagnosis (various types of asymmetries) ${ }^{9}$, making quantitative determinations for the correction of each segment of the face ${ }^{10}$, planning necessary corrections and determining exactness of the techniques used $^{11,12}$. Bilateral balance of soft and hard tissue between these lines and planes creates what is known as a symmetric face, which may not necessarily be subjectively pleasing to the human eye. A beautiful facial profile is one where facial segments are aligned along the facial plane/planes², which, when implied to natural dentition means that dental midlines should not only correspond to, but in fact have a proper relationship to the face. A symmetric dentition in relation to facial midline is an important contributor to facial aesthetics ${ }^{13}$. Facial and dental asymmetry vary racially, across genders and could be also because of underlying hard and soft tissues variations ${ }^{14,15}$. Correlation between the two midlines (facial and dental) vary between professionals as well as between dentist and patients also ${ }^{16}$. Besides size, shape, color and position of the natural or artificial teeth, concepts like golden and red proportion, golden percentage have also evolved in the field of dynaesthetics ${ }^{17-19}$.

Historically, a number of facial landmarks such as; the bisector of interpupillary line, nasion, tip of nose, tip of the philtrum and chin have been used to determine the facial and dental midlines ${ }^{20,21}$. Even intraoral landmarks like incisive papilla have been used for determination of maxillary dental midline. Clinical studies mentioned in the literature are limited to amount of tolerance of deviated dental midlines from facial midline (span of nearly 2-3 mm) ${ }^{22}$. This has led clinician to a situation with no predictable guidelines and most determine the midline based on non-verified landmarks. This study is an attempt to utilize clinical landmark like interpupillary distance to determine the facial midline and then see the relation between the maxillary and mandibular dental midlines to the facial midline. This will allow the clinician to use the investigated landmark for aesthetic midline reference in the field of orthognathic surgery, orthodontics, restorative, cosmetic dentistry and prosthetic rehabilitation through removable and fixed prosthodontics. The study has been also be a part of continuing data collection for forensic purpose in the investigated population sample.

\section{MATERIALS AND METHODS}

Study setting and sample collection: The study was carried out at the Department of Prosthodontics, post-graduate section from April, 2014-March, 2016. This cross sectional, descriptive study was conducted on a sample of 100 North Indian young individuals. Subjects were analyzed for possessing aesthetically pleasing face which was examined and selected by a panel of five members (prosthodontist, restorative dentist, orthodontist, plastic surgeon and ear, nose and throat specialist) having expertise in facial aesthetics. The selection was done clinically after identifying subjects from standard photographs. Subjects selected for final study included 70 females and 30 males between the age group of 21-25 years. Selection criteria included bilaterally symmetrical face, proportionate length and width of face, fully erupted natural dentition with no evidence of wear and centric discrepancy, no hair loss, absence of any eye disorder and absence of any evident deviated nasal septum. Ethical clearance was obtained from the university ethical committee which conducts human research as per Helsinki declaration ${ }^{23}$ while an informed consent were obtained from each subject before commencing the study.

Measurement: The interpupillary distance was measured as by the method described by Gupta et al.24. Once the midline of the face was marked using a facial midline locator (Fig. 1a), it was transferred to the natural teeth by using a modified face bow called facial-dental midline relator (Fig. 1b). The relator comprised of a U-shaped aluminium frame which had two horizontal arms attached to a crossbar that extends to accommodate the head of the subjects. The crossbar had a centre pin and a horizontal leveller (spirit level). To adjust the entire assembly in the centre of the face, two adjustable horizontal rods with earpiece were provided which could be fitted and locked in place on a graduated scale in the external auditory meatus. A centre pin was provided th the mid-point of the crossbar in a rectangular slot, so that it could move only in one direction i.e., anterior and posterior direction. The whole procedure of marking the facial midline and transferring it to the natural dentition was completed within 10-15 min. The maxillary and mandibular midlines were 

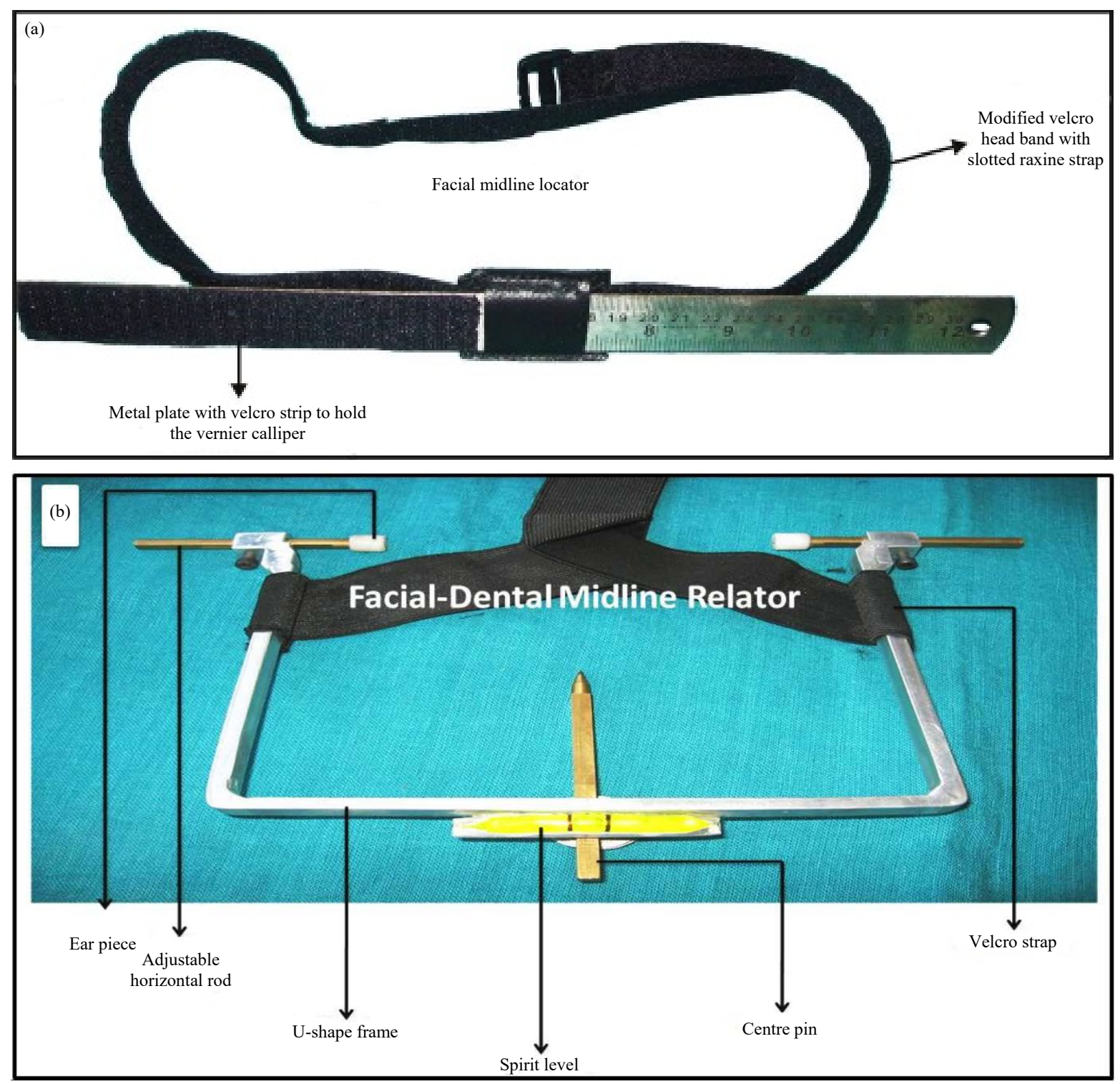

Fig. 1(a-b): (a) Facial midline locator and (b) Facial dental midline relator

analyzed directly on the patient using a probe to measure the discrepancy between the two midlines at the level of mesial surface of both central incisors. Midlines which fell within a distance of $1 \mathrm{~mm}$ from each other were considered as coinciding. Data collection was done for each subject by measuring the amount of discrepancy between maxillary midline and facial midline, maxillary and mandibular midlines and mandibular midline and facial midline.

Statistical analysis: Data gathered from each subject for each parameter was entered into an excel sheet which was later coded for analysis. Data collected was entered into SPSS 25 following which frequencies in term of percentage was done.
Mean and standard deviation were calculated which were then analyzed using unpaired t-test for statistical significance which was determined at a $p<0.01$.

Ethics: The research proposal was duly approved by the research committee of the college that falls within the deanship of scientific research for post-graduate studies of the university. All research undertaken by the university strictly adheres to the guidelines in accordance to the Helsinki declaration. A written informed consent duly approved by the research committee and signed by the subjects participating in the study was obtained as part of maintaining ethical standards of human research. 


\section{RESULTS}

Midline variations: Three individual midlines were investigated namely facial midline, maxillary and mandibular dental midline. Table 1 shows the variations in term of frequencies, means, standard deviations and coefficient of variation between various midlines. Forty percent of subjects showed maxillary dental midline coinciding with facial midline while another $47 \%$ were between 1-2 mm. The two dental midlines were not coinciding in $60 \%$ of subjects while the mandibular dental midline demonstrated greater fluctuation in distances with $45 \%$ of subjects having a discrepancy of between $2.6-3 \mathrm{~mm}$ on either side.
Significance of variations: Table 2 shows the relation between the investigated parameters after application of unpaired t-test. The differences between the maxillary dental midline and the facial midline and the mandibular midline with the facial midline showed statistical significance at $p<0.01$. However there was no statistical significance of the differences between the maxillary dental midline and the mandibular dental midline in the studied population. A comparison of various distances that each midline presented in the studied sample is shown in Fig. 2. The maximum variation that was shown among subjects was between the mandibular dental midline and maxillary dental midline (60\%) for the measured distance of upto $1 \mathrm{~mm}$. The minimum variation exhibited for distance between $2.6-3 \mathrm{~mm}$ between

Table 1: Variation between various midlines

\begin{tabular}{|c|c|c|c|c|c|c|c|}
\hline Variation in parameter & Grades & Upto $1 \mathrm{~mm}$ & $1.1-1.5 \mathrm{~mm}$ & $1.6-2 \mathrm{~mm}$ & $2.1-2.5 \mathrm{~mm}$ & $2.6-3 \mathrm{~mm}$ & $3 \mathrm{~mm}$ above \\
\hline \multirow[t]{4}{*}{ Maxillary dental midline from facial midline } & Percentage & $40 \%$ & $21 \%$ & $26 \%$ & $7 \%$ & $6 \%$ & - \\
\hline & Mean & 0.2675 & 1.2857 & 1.7884 & 2.2714 & 2.7333 & - \\
\hline & SD & 0.0381 & 0.1424 & 0.1275 & 0.138 & 0.1366 & - \\
\hline & CV & 142.504 & 11.075 & 7.1292 & 6.0755 & 4.9976 & - \\
\hline \multirow[t]{4}{*}{ Mandibular dental midline from maxillary dental midline } & Percentage & $60 \%$ & $20 \%$ & $10 \%$ & $8 \%$ & $1 \%$ & \\
\hline & Mean & 0.2416 & 1.255 & 1.78 & 2.35 & - & - \\
\hline & SD & 0.3958 & 0.1431 & 0.1549 & 0.1309 & - & - \\
\hline & CV & 163.82 & 11.40 & 8.702 & 5.57 & - & - \\
\hline \multirow[t]{4}{*}{ Mandibular dental midline from facial midline } & Percentage & $11 \%$ & $15 \%$ & $15 \%$ & $14 \%$ & $45 \%$ & - \\
\hline & Mean & 0.7181 & 1.62 & 2.522 & 3.49 & 4.572 & - \\
\hline & SD & 0.3347 & 0.3254 & 0.3304 & 0.3057 & 0.4991 & - \\
\hline & CV & 80.05 & 20.08 & 13.10 & 0.087 & 10.916 & - \\
\hline
\end{tabular}

SD: Standard deviation, CV: Coefficient of variation

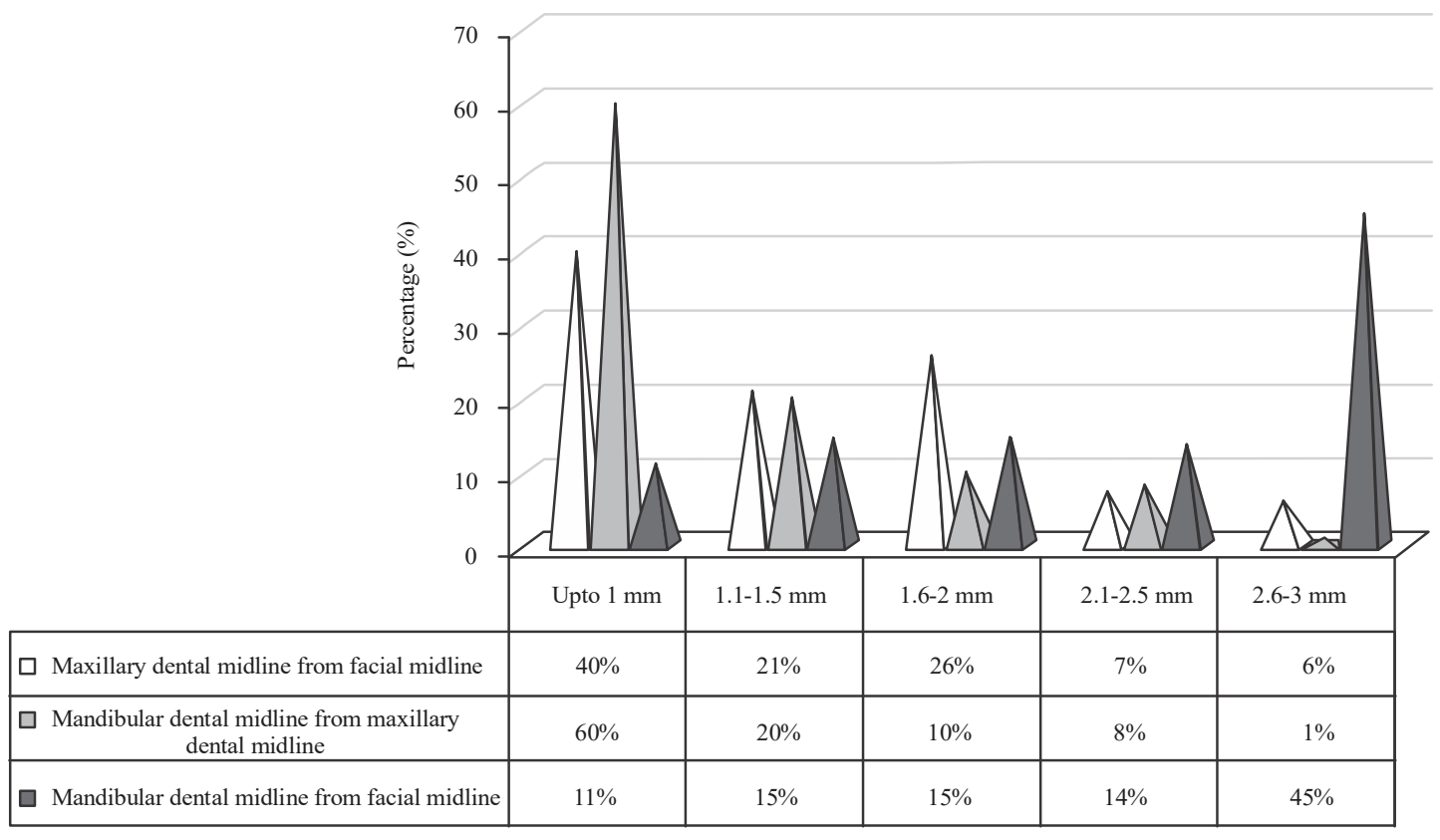

Fig. 2: Graphical representation of variation among various midlines that assist in determination of aesthetics 
Singapore J. Sci. Res., 10 (4): 363-369, 2020

Table 2: Relation between various parameters and their level of significance

\begin{tabular}{|c|c|c|c|}
\hline & Maxillary dental midline and facial midline ${ }^{\#}$ & Maxillary and mandibular dental midline ${ }^{\#}$ & Mandibular dental midline and facial midline \\
\hline Mean $\pm S D$ & $1.125 \pm 0.8566$ & $0.801 \pm 0.8259$ & $2.132 \pm 1.302$ \\
\hline Standard error of mean & 0.0856 & 0.0825 & 0.1302 \\
\hline Coefficient of variation & 76.142 & 103.108 & 56.413 \\
\hline t cal & 13.6002 & 0.9709 & 3.343 \\
\hline p-value & $\mathrm{p}<0.01^{*}$ & $p>0.01$ & $\mathrm{p}<0.01^{*}$ \\
\hline
\end{tabular}

mandibular and maxillary dental midlines. Uniform distribution between various midlines was seen for the category of variation between 1.1-1.5 mm. Among various midlines the greatest variation existed that of mandibular dental midline which varied to a distance of $2.6-3 \mathrm{~mm}$ in $45 \%$ of the subjects.

\section{DISCUSSION}

The present study was conducted on the North Indian subjects and therefore the data generated through this study is valid for the concerned population only. The feature of the study is the development of a clinical device to measure interpupillary distance from which facial midline can be calculated. Since the method is clinical, it omits the drawbacks that are associated with measuring interpupillary distance using radiographic and photographic techniques. The main objective of the study was to evaluate the correlation of dental midline and facial midline. The study was conducted on subjects whose age ranged between 21-25 years since the interpupillary distance remains constant after this period of life. The IPD values generated among subjects were $53-66 \mathrm{~mm}$ for female subjects and $59-70 \mathrm{~mm}$ for male subjects. From the $I P D$, it was calculated the facial midline and maxillary midline varied about $1 \mathrm{~mm}$ from this midpoint in $40 \%$ of subjects while only $6 \%$ of individuals showed deviation between the two in the range of 2-3 $\mathrm{mm}$. On the contrary the mandibular dental midline showed deviation of more than $2 \mathrm{~mm}$ in $45 \%$ of the individuals thus, suggested the non-reliability of the landmark in determining aesthetics. These results can be explained on the basis of anatomic connection between the cranium and the mandible. The natural teeth in the maxillary arch are part of the cranium and the connection between them is through sutures. The mandible on the other hand is connected to the cranium (where facial midline is determined) through the temporomandibular joint through articular disc which is compressible and displaceable. A minimal deviation at the level of the temporomandibular joint is magnified at any level far away from it (in this case mandibular dental midline). The variation of the mandibular dental midline from the maxillary dental midline is based on the relation of the occlusion. The mandibular teeth intercuspate during closure and since maxillary arch cannot shift, the mandible shifts because it can in either direction. Clinically the observance of mandibular dental midline is done in centric occlusion which implicated that the teeth are in occlusion and any discrepancy of teeth pushes the mandible to right or left thus explaining the non-coincidence of mandibular dental midline to either facial or maxillary dental midline.

Determining facial midline is an important clinical landmark in medical treatments like plastic surgery while it is essential in most of specialized dental practices. There are different ways to measure the interpupillary line. The IPD values observed in our study of North Indian females was 53-66 $\pm 4 \mathrm{~mm}$ and in males was $59-70 \pm 4.22$ and are found to be within the values obtained by Gupta et al.24. Majority of the subjects in the study show maxillary dental midline either coinciding with facial midline or falling within the range of 1-2 $\mathrm{mm}$ beyond it. Since, the center of the pupil cannot be used to measure interpupillary distance we used the method described by Osubeni and Al Gharni ${ }^{25}$. The method utilized temporal limbus of one eye and nasal limbus of other and is a reliable clinical method ${ }^{25}$ as it is not affected by light intensity, size of pupil and its contrast with the surrounding pigmented iris. These results are in accordance with Beyer and Lindauer ${ }^{22}$ who found that varying thresholds of acceptability of midline exist among individuals by even $2-3 \mathrm{~mm}$. The deviation of the dental midline from the facial midline could be as a result of discrepancy between skeletal and dental components of the face. It may also be as a result of difference in size, shape and form of the natural teeth with respect to the subjects face form. Deviation towards right was found more than deviation towards left. Increased lower facial third length was associated with variations in all three segments ranging between 1.7-2 $\mathrm{mm}$. The maxillary dental midline ranks closest to facial midline than the mandibular midline. Significant relation exists between maxillary midline and facial midline in this study which disagree with the findings by Eskelson et al. ${ }^{26}$. They concluded that there was no relation between the maxillary midline and bisector to interpupillary line. However the difference could be because of the method used to 
measure interpupillary distance. Consensus regarding determination of facial midline has not yet reached since many studies consider different landmarks for determining facial midline. Some anatomical landmarks that have been investigated are midline of commissures, tip of philtrum and dental midline ${ }^{27}$. Although difficulty in measuring correct inter-pupillary distance exist but pupils are more reliable than the soft tissue landmarks around the mouth since they are affected by the quantity, tone and overall body mass index of an individual. Moreover aging changes also do occur that changes the dynamic relation of soft tissue landmarks. Similar results were obtained for the relation of mandibular dental midline with facial midline and the differences were statistically significant at $p<0.01$. There were no statistical differences in relation between maxillary and mandibular dental midlines which is in accordance with earlier studies ${ }^{14,20}$.

\section{CONCLUSION}

Within the limitation of this study it can be concluded that the maxillary dental midline coincides with facial midline in most of individuals and deviation if any should be between 1-2 mm for anterior prosthesis. Facial midline should be considered during diagnosis and treatment plan for any restoration that involves maxillary anterior teeth. Whenever other guidelines are absent facial midline should be considered for selection of size of maxillary anterior teeth.

\section{SIGNIFICANCE STATEMENT}

The significance of this study is its applicability by multiple professionals like restorative dentist, prosthodontist, plastic surgeons, orthodontist and general reconstructive facial surgeons. Since this study is an analytical descriptive study, it therefore fulfills the objective of analysis which is a continuous process that can be used in future for reference. An important aspect of this study is the use of an innovative, simple, non-expensive yet highly accurate method of recording facial midline.

\section{REFERENCES}

1. Broadbent, T.R. and V.L. Mathews, 1957. Artistic relationships in surface anatomy of the face: Application to reconstructive surgery. Plast. Reconstr. Surg., 20: 1-17.

2. Mario, G.U., 1962. Quantitative principles in cosmetic surgery of the face (Profileplasty). Plast. Reconstr. Surg., 29: 186-198.
3. Tjan, A.H.L., G.D. Miller and J.G.P. Dent, 1984. Some esthetic factors in a smile. J. Prosthetic Dent., 51: 24-28.

4. Peck, H. and S. Peck, 1970. A concept of facial esthetics. Angle Orthod., 40: 284-318.

5. Frush, J.P. and R.D. Fisher, 1958. The dynesthetic interpretation of the dentogenic concept. J. Prosthetic Dent., 8: 558-581.

6. Rosenstiel, S.F., D.H. Ward and R.G. Rashid, 2000. Dentists' preferences of anterior tooth proportion-A web-based study. J. Prosthodontics, 9: 123-136.

7. Wilkinson, C.M., M. Motwani and E. Chiang, 2003. The relationship between the soft tissues and the skeletal detail of the mouth. J. Forensic Sci., 48: 728-732.

8. Stephan, C. and M. Henneberg, 2003. Predicting mouth width from inter-canine width-a $75 \%$ rule. J. Forensic Sci., 48: 725-727.

9. Bishara, S.E., P.S. Burkey and J.G. Kharouf, 1994. Dental and facial asymmetries: A review. Angle Orthod., 64: 89-98.

10. Lombardi, R.E., 1974. A method for the classification of errors in dental esthetics. J. Prosthetic Dent., 32: 501-513.

11. Scandrett, F.R., P.E. Kerber and Z.R. Umrigar, 1982. A clinical evaluation of techniques to determine the combined width of the maxillary anterior teeth and the maxillary central incisor. J. Prosthetic Dent., 48: 15-22.

12. Fayyad, M.A., K.D. Jamani and J. Agrabawi, 2006. Geometric and mathematical proportions and their relations to maxillary anterior teeth. J. Contemp. Dent. Pract., 7: 62-70.

13. Kokich, V.O., V.G. Kokich and H.A. Kiyak, 2006. Perceptions of dental professionals and laypersons to altered dental esthetics: Asymmetric and symmetric situations. Am. J. Orthod. Dentofacial Orthopedics, 130: 141-151.

14. Miller, E.L., Jr.W.R. Bodden and H.C. Jamison, 1979. A study of the relationship of the dental midline to the facial median line. J. Prosthetic Dent., 41: 657-660.

15. McVay, T.J. and G.H. Latta Jr., 1984. Incidence of the maxillary midline diastema in adults. J. Prosthetic Dent., 52: 809-811.

16. Brisman, A.S., 1980. Esthetics: A comparison of dentists' and patients' concepts. J. Am. Dent. Assoc., 100: 345-352.

17. Levin, E.I., 1978. Dental esthetics and the golden proportion. J. Prosthetic Dent., 40: 244-252.

18. Preston, J.D., 1993. The golden proportion revisited. J. Esthetic Restor. Dent., 5: 247-251.

19. Lombardi, R.E., 1973. The principles of visual perception and their clinical application to denture esthetics. J. Prosthetic Dent., 29: 358-382.

20. Bidra, A.S., F. Uribe, T.D. Taylor, J.R. Agar, P. Rungruanganunt and W.P. Neace, 2009. The relationship of facial anatomic landmarks with midlines of the face and mouth. J. Prosthetic Dent., 102: 94-103.

21. Cardash, H.S., Z. Ormanier and B.Z. Laufer, 2003. Observable deviation of the facial and anterior tooth midlines. J. Prosthetic Dent., 89: 282-285. 
22. Beyer, J.W. and S.J. Lindauer, 1998. Evaluation of dental midline position. Semin. Orthodontics, 4: 146-152.

23. World Medical Association, 2013. World Medical Association Declaration of Helsinki: Ethical principles for medical research involving human subjects. J. Am. Med. Assco., 310: 2191-2194.

24. Gupta, V.P., P.K. Sodhi and R.M. Pandey, 2003. Normal values for inner intercanthal, interpupillary and outer intercanthal distances in the Indian population. Int. J. Clin. Pract., 57: 25-29.
25. Osuobeni, E.P. and S.S. Al-Gharni, 1994. Ocular and facial anthropometry of young adult males of Arab origin. Optometry Vision Sci., 71: 33-37.

26. Eskelsen, E., C.B. Fernandes, F. Pelogia, L.G. Cunha, D. Pallos, M.P. Neisser and P.C.S. Liporoni, 2009. Concurrence between the maxillary midline and bisector to the interpupillary line. J. Esthetic Restor. Dent., 21: 37-41.

27. Mavroskoufis, F. and G.M. Ritchie, 1981. Nasal width and incisive papilla as guides for the selection and arrangement of maxillary anterior teeth. J. Prosthetic Dent., 45: 592-597. 